$$
\begin{array}{ll}
\text { Research Square } & \begin{array}{l}
\text { Preprints are preliminary reports that have not undergone peer review. } \\
\text { They should not be considered conclusive, used to inform clinical practice, } \\
\text { or referenced by the media as validated information. }
\end{array}
\end{array}
$$

\title{
Assessing Phenylalanine Blood Level in Children Having Phenylketonuria in Southern Khorasan Province, and Determining the Affecting Social and Demographic Factors
}

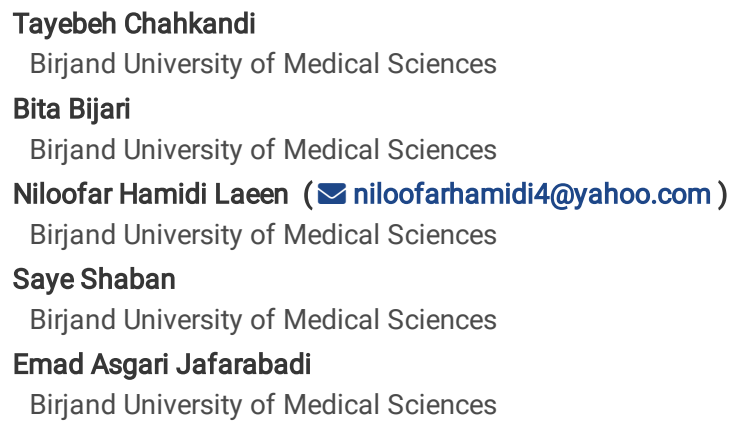




\section{Abstract}

Background: Phenylketonuria is a metabolic disorder resulting from a defect in phenylalanine metabolism with a global prevalence of 1 in 10000 . Delayed initiation of dietary modification leads to brain injury and cognitive and behavioral problems. The main objective of this study was to assess the demographic and social factors affecting metabolic control of patients having phenylketonuria in Southern Khorasan Province.

Methods: In this cross-sectional descriptive analytic study which was performed during summer 2019, 32 out of 37 known children and adolescents having phenylketonuria in Southern Khorasan Province were assessed. The age of patients, the gender of patients, parentsmaritalstatus, parents occupational status, parents' educational level, the distance between home and phenylketonuria clinic, and the number of affected siblings having phenylketonuria were documented. We were not able to contact five patients having phenylketonuria in Southern Khorasan Province. Data were analyzed by SPSS 16 software using Mann-Whitney U test and Kruskal-Wallis test. The significance level was considered as $p<0.05$.

Results: 32 patients with a mean age of $6.6 \pm 4.7$ years were enrolled in this study. 23 of them were male ( $71.9 \%)$ and 9 patients were females ( $28.1 \%)$. The mean phenylalanine level in this study group was $8.1 \pm 5.2 \mathrm{mg} / \mathrm{dl}$. The disease was optimally controlled in 14 patients (43.3\%) and poorly controlled in 18 of them (56.3\%). There was not any statistically significant relation between the metabolic control of the disease and any of the assessed social and demographic factors.

Conclusion: The disease was properly controlled in $43.3 \%$ of the assessed population, and $56.3 \%$ had poor metabolic control. There was not any statistically significant relation between the metabolic control of patients having phenylketonuria in Southern Khorasan Province and assessed demographic and social. As the number of known cases in South Khorasan province is limited, small sample size could be one of the main limitations of our study.

\section{1- Background}

Phenylketonuria is an autosomal recessive genetic disorder. The estimated worldwide incidence is 1 in 10000 [1]. According to the data obtained from neonatal screening between 2000 and 2005 in the Fars province of Iran, an incidence of 1 in 4698 was reported [3] An incidence of 1 in 6662 live births was also reported in the Chaharmahalobakhtiari province of Iran between 2012 and 2015 [4]. According to another study performed between 2010 and 2011 in Yazd province on 22131 neonates, an incidence of 1.8 in 10000 births was reported. [8] Consanguinity is thought to be the most important factor regarding the higher incidence of this disease in some parts of the world [2]. Phenylketonuria is the most common disorder of amino acids metabolism [10].

Normally ingested phenylalanine is metabolized to tyrosine through the action of phenylalanine hydroxylase and a cofactor called tetrahydrobiopterin. Deficient phenylalanine hydroxylase cannot metabolize phenylalanine to tyrosine, which leads to phenylalanine accumulation in body. [11] Phenylalanine accumulation mainly damages the Brain. Normally, subsequent metabolic processes convert tyrosine to a number of metabolites including skin and hair pigments, and final metabolites are excreted from the body [30]. Over 950 genes are associated with phenylalanine hydroxylase deficiency [6]. Measuring phenylalanine blood level is a practical and reliable method to diagnose the disease and monitor the treatment course [5]. In classic phenylketonuria phenylalanine blood level is more than $20 \mathrm{mg} / \mathrm{dl}$. Following strict specific diets in which the consumption of natural proteins is restricted and instead amino acid formulas are consumed, phenylalanine intake is limited and brain damage is prevented. The specific diet must be followed throughout life [7]. Every 1.66 $\mathrm{mg} / \mathrm{dl}$ increase in phenylalanine blood level is associated with 1.3 up to 3.1 points reduction in Intelligence Quotient (IQ) [5]. Phenylketonuria is the first metabolic and genetic disorder which has been successfully treated [12]. According to the Iranian national phenylketonuria guideline, the accepted phenylalanine level is $2-6 \mathrm{mg} / \mathrm{dl}$ and $2-10 \mathrm{mg} / \mathrm{dl}$ for those under 12 years old and those over 12 years old respectively.

Normally a limited amount of phenylalanine is metabolized to phenylketones, including phenylpyruvate, phenylacetate and phenyllactate; in patients having phenylketonuria, high amounts of phenylketones are produced. High phenylpyruvate level interferes with myelin synthesis in brain, leading to mental retardation. Another proposed cause of mental retardation in these patients is deficient synthesis of neurotransmitter dopamine, which is normally synthesized from tyrosine. Normally the only source of tyrosine production in human body is the metabolism of phenylalanine trough the action of phenylalanine hydroxylase; as a result tyrosine is an essential amino acid in patients having phenylketonuria which must be obtained through appropriate diet.

The early weeks of life is a critical period for the developing brain of the infant, and feeding infants having phenylketonuria with breast milk and normal formulas could cause irreversible neurologic damage, and later treatments and therapeutic diets would not be effective.

Untreated infants present later in life with developmental delay, vomiting, growth retardation, seizure, blond hair and blue eyes. During early childhood, microcephaly, restlessness, attention deficit, repetitive limbs movement and mental retardation are among other manifestations. The presence of excessive amount of phenylalanine metabolites is the cause of musty urine odor in untreated patients. Urticarial skin Rash is one of the other presentations of untreated patients.

The disease could be screened from day two of life onward, using a blood or urine sample. A phenylalanine blood level of $20 \mathrm{mg} / \mathrm{dl}$ or more is suggestive of phenylketonuria. As a result of early diagnosis and administration of specific formulas to affected infants, affected children could have normal intelligence and brain function. The goal of treatment is to reduce phenylalanine blood level to a safe amount. During infancy and childhood, patients can consume a variety of foods including vegetables, fruits, starch, fat, rice, breads and a limited amount of grains. Blood phenylalanine level should be checked regularly. According to blood phenylalanine level, the diet of each patient must be planned by a dietician. The recommended diet must be followed throughout life [30]. It is notable that despite early diagnosis and appropriate therapeutic diet, patients having phenylketonuria may have problems in maintaining attention and poor academic performance. [13] 
Assessing possible factors that might affect patients

adherence $\rightarrow$ thetherapeuticdietcodbeanimp or tantprogress $\in$ a $\chi$ ev $\in$ gbeercaref or them. A or $d \in g \rightarrow$ asystematicreviewartic $\leq$ byM $\epsilon$

educational level, child knowledge about phenylketonuria, parent employment or occupational status, and the number of siblings with phenylketonuria are factors that have significant positive correlation with phenylalanine blood level. The authors of this review article state that there is a paucity of studies examining the potential demographic or psychosocial influences on metabolic control of patients having phenylketonuria, which could be due to the rarity of this disease and small sampling pool. [7]

In 2011 during a study performed on 105 children having phenylketonuria at Mofid hospital, Tehran, the following factors were found to be correlated with the metabolic control of these patients. Metabolic control was better in those under 12 years old. The number of siblings having phenylketonuria, divorced parents, and occupational status of parents were among other affecting factors. The authors concluded that the social status of patients affect phenylalanine level to some degree. [18]

In a study performed by Mahmoudi-Gharaei et al., 49 care givers of children having phenylketonuria who were presented to a psychiatry outpatient clinic were assessed. Based on the results of this study, 57.1 per cent and 50.1 percent of caregivers had depression and anxiety respectively; and employment status played a meaning full role regarding their mental health. The authors recommended performing similar studies in other parts of Iran. [19]

Considering the lack of similar studies in the eastern part of Iran, this study was conducted to assess the effect of a number of suggested socioeconomic factors that are presumed to be correlated with phenylalanine blood level.

\section{2- Methods}

This is a cross-sectional descriptive analytic study which was conducted in summer 2019 in South Khorasan Province, Iran. 32 out of 37 known children and adolescents having phenylketonuria in Southern Khorasan Province were assessed.

\section{2-1. Inclusion Criteria}

The main inclusion criteria were as follow:

- Living in south Khorasan province

- To be under 18 years of age

\section{2-2. Exclusion Criteria}

The main exclusion criteria were as follow:

- The dissatisfaction of the patient or legal guardian for participation in the research

\section{2-3. Sample Size:}

There were 37 known cases of phenylketonuria under 18 years old at time of performing this study in South Khorasan province. 32 patients and their families were thoroughly interviewed and assessed; it was not possible to contact five cases, so the sample size was 32.

\section{2-4. Method}

Age, sex, family composition factors including separated parents or cohabitant parents, occupational status of parents, living in Birjand city were the phenylketonuria clinic is located or living out of Birjand city, and the number of siblings having phenylketonuria were the socioeconomic factors that were assessed among children and adolescence having phenylketonuria in South Khorasan province, and the relation of these factors with metabolic control of the disease were assessed. It must be noted that Birjand is the capital of South Khorasan Province.

Data was gathered during regular and periodic visits of patients at the main phenylketonuria clinic of South Khorasan province, in Valieasr hospital. In order to assess the metabolic control of patients, the mean blood phenylalanine of patients was also recorded. According to the Iranian National Phenylketonuria guideline, the acceptable blood phenylalanine level of patients aged below 12 years old, and those above 12 years old are 2-6 mg/dl and 2-10 mg/dl respectively; a mean blood phenylalanine blood level above the mentioned values is indicative of poor metabolic control.

\section{2-5. Data Analysis}

Data were analyzed using the SPSS software version 22.0 using the Kolmogorov-Smirnov test to show the normal distribution of data. As blood phenylalanine level was not normally distributed ( $p=0.007$ ), Mann-Whitney U Test and Kruskal Wallis Test were used to compare the mean phenylalanine blood level of patients based on their demographic and socioeconomic condition. A p-value of less than 0.05 was considered a statically significant difference.

Loading [MathJax]/jax/output/CommonHTML/fonts/TeX/fontdata.js 


\section{3- Results}

32 patients with a mean age of $6.6 \pm 4.7$ years old were enrolled in this study; the lowest recorded age was one year old and the highest was 18 years old. 71.9 per cent of patients were male. The demographic characteristics of patients and their families are presented in Table-1.

Table-1

Demographic characteristics of patients and families, their number and relative frequencies

\begin{tabular}{|lll|}
\hline Sex & Male & $23(71.9 \%)$ \\
\cline { 2 - 3 } & Female & $9(28.1 \%)$ \\
\hline Parents` educational status & Under 6 years old & $18(56.3 \%)$ \\
\cline { 2 - 3 } & Above 6 years old & $14(43.8 \%)$ \\
\hline Family composition & Illiterate & $3(9.4 \%)$ \\
\cline { 2 - 3 } & High school (under graduate) & $12(37.5 \%)$ \\
\cline { 2 - 3 } & Diploma education & $11(34.4 \%)$ \\
\cline { 2 - 3 } & University education & $6(18.8 \%)$ \\
\hline Father`s occupational status & Cohabitant parents & $30(93.8 \%)$ \\
\cline { 2 - 3 } & Separated parents & $2(6.3 \%)$ \\
\hline Place of residence & Employed & $28(87.5 \%)$ \\
\cline { 2 - 3 } & Unemployed & $4(12.5 \%)$ \\
\hline The number of affected siblings having PKU & Inside Birjand city & $18(56.3 \%)$ \\
\cline { 2 - 3 } & Outside of Birjand city & $14(43.8 \%)$ \\
\hline & 2 & $25(71.8 \%)$ \\
\hline
\end{tabular}

The mean blood phenylalanine level was $8.1 \pm 5.2 \mathrm{mg} / \mathrm{dl}$. The minimum and maximum blood phenylalanine levels were $0.4 \mathrm{mg} / \mathrm{dl}$ and $21.4 \mathrm{mg} / \mathrm{dl}$ respectively.

According to the data presented in table 2 , none of the assessed demographic and social factors were statistically related to blood phenylalanine level.

\section{Table-2}

Comparison of blood phenylalanine level based on social and demographic characteristics of patient 


\begin{tabular}{|c|c|c|c|c|c|}
\hline Demographic factor & & $\begin{array}{l}\text { Mean } \pm \text { Standard } \\
\text { deviation }\end{array}$ & $\begin{array}{l}\text { Median (25th and } 75 \text { th } \\
\text { quartile) }\end{array}$ & Statistic & $\begin{array}{l}\mathrm{p}- \\
\text { value }\end{array}$ \\
\hline \multirow[t]{2}{*}{ Sex } & Female & $8.78 \pm 5.38$ & $7.4(4.6-12.8)$ & \multirow[t]{2}{*}{1.17} & \multirow[t]{2}{*}{0.24} \\
\hline & Male & $6.34 \pm 4.68$ & $6.5(2-10.1)$ & & \\
\hline \multirow[t]{2}{*}{ Age } & Below 6 years & $7.12 \pm 3.77$ & $6(4.3-8.3)$ & \multirow[t]{2}{*}{0.76} & \multirow[t]{2}{*}{0.44} \\
\hline & Above 6 years & $9.35 \pm 6.58$ & $7.7(3.2-14.8)$ & & \\
\hline \multirow[t]{4}{*}{ Parents` educational status } & Illiterate & $12 \pm 4.08$ & $14(73-14)$ & \multirow[t]{4}{*}{2.4} & \multirow[t]{4}{*}{0.48} \\
\hline & $\begin{array}{l}\text { High school } \\
\text { (undergraduate) }\end{array}$ & $6.30 \pm 3.46$ & $6.6(3.5-8.1)$ & & \\
\hline & Diploma education & $9.43 \pm 6.91$ & $6.5(3.4-17.4)$ & & \\
\hline & University education & $7.31 \pm 4.31$ & $6.4(4.1-9.4)$ & & \\
\hline \multirow[t]{2}{*}{ Family composition } & Cohabitant parents & $8.19 \pm 5.37$ & $7.3(4.1-12.4)$ & \multirow[t]{2}{*}{0.0 .3} & \multirow[t]{2}{*}{0.96} \\
\hline & Separated parents & $6.66 \pm 1.89$ & $6.6(5.3-6.6)$ & & \\
\hline \multirow[t]{2}{*}{ Father`s occupational status } & Employed & $8.42 \pm 5.38$ & $6.9(4.2-12.6)$ & \multirow[t]{2}{*}{0.54} & \multirow[t]{2}{*}{0.60} \\
\hline & Unemployed & $5.85 \pm 3.64$ & $7.5(2.1-7.9)$ & & \\
\hline \multirow[t]{2}{*}{ Place of residence } & Inside Birjand city & $9.11 \pm 5.51$ & $7.7(5.4-12.4)$ & \multirow[t]{2}{*}{1.5} & \multirow[t]{2}{*}{0.12} \\
\hline & Outside of Birjand city & $6.80 \pm 4.68$ & $4.9(3.2-9.5)$ & & \\
\hline \multirow{2}{*}{$\begin{array}{l}\text { The number of affected siblings having } \\
\text { PKU }\end{array}$} & 1 & $7.38 \pm 4.52$ & $7.3(4.2-8.7)$ & & \\
\hline & 2 & $10.67 \pm 7.00$ & $14(3-17.4)$ & & \\
\hline
\end{tabular}

Although there are differences between the blood phenylalanine level of patients with different demographic and social characteristics, but the differences are not statistically significant.

As depicted in Fig. 1, the metabolic control of 14 patients (43.3\%) was acceptable, and 18 patients (56.3\%) had poorly controlled blood phenylalanine levels.

Table 3 presents comparison of the metabolic control of patients based on their social and demographic characteristics. 
Table 3

Comparison of the metabolic control of patients based on their social and demographic characteristics

\begin{tabular}{|c|c|c|c|c|c|}
\hline Demographic factor & & $\begin{array}{l}\text { Number of patients with good } \\
\text { metabolic control (percentage) }\end{array}$ & $\begin{array}{l}\text { Number of patients with poor } \\
\text { metabolic control (percentage) }\end{array}$ & Statistic & $\begin{array}{l}\mathrm{P} \text { - } \\
\text { value }\end{array}$ \\
\hline \multirow[t]{2}{*}{ Sex } & Male & $10(43.5 \%)$ & $13(54.6 \%)$ & \multirow{2}{*}{$\begin{array}{l}X^{2}=0.002 \\
D F=1\end{array}$} & \multirow[t]{2}{*}{0.63} \\
\hline & Female & $5(55.6 \%)$ & $4(44.4 \%)$ & & \\
\hline \multirow[t]{2}{*}{ Age } & Below 6 years & $9(50 \%)$ & $9(50 \%)$ & \multirow{2}{*}{$\begin{array}{l}X^{2}=0.65 \\
D F=1\end{array}$} & \multirow[t]{2}{*}{0.32} \\
\hline & Above 6 years & $5(35.7 \%)$ & $9(64.3 \%)$ & & \\
\hline \multirow[t]{2}{*}{ Place of residence } & $\begin{array}{l}\text { Inside Birjand } \\
\text { city }\end{array}$ & $6(33.3 \%)$ & $12(66.7 \%)$ & \multirow{2}{*}{$\begin{array}{l}X^{2}=0.18 \\
D F=1\end{array}$} & \multirow[t]{2}{*}{0.16} \\
\hline & $\begin{array}{l}\text { Outside of } \\
\text { Birjand city }\end{array}$ & $8(57.1 \%)$ & $6(42.9 \%)$ & & \\
\hline \multirow{4}{*}{$\begin{array}{l}\text { Parents` educational } \\
\text { status }\end{array}$} & Illiterate & $0(0.00 \%)$ & $3(100.00 \%)$ & \multirow{4}{*}{$\begin{array}{l}\text { Fisher exact } \\
\text { test }=2.4\end{array}$} & \multirow[t]{4}{*}{0.56} \\
\hline & $\begin{array}{l}\text { Highschool } \\
\text { (undergraduate) }\end{array}$ & $6(50.0 \%)$ & $6(50.0 \%)$ & & \\
\hline & $\begin{array}{l}\text { Diploma } \\
\text { education }\end{array}$ & $5(45.5 \%)$ & $6(54.5 \%)$ & & \\
\hline & $\begin{array}{l}\text { University } \\
\text { education }\end{array}$ & $3(50 \%)$ & $3(50 \%)$ & & \\
\hline \multirow[t]{2}{*}{ Family composition } & $\begin{array}{l}\text { Cohabitant } \\
\text { parents }\end{array}$ & $13(43.7 \%)$ & $17(56.7 \%)$ & \multirow[t]{2}{*}{$\begin{array}{l}\text { Fisher exact } \\
\text { test }\end{array}$} & \multirow[t]{2}{*}{1} \\
\hline & $\begin{array}{l}\text { Separated } \\
\text { parents }\end{array}$ & $1(50.0 \%)$ & $1(50.0 \%)$ & & \\
\hline \multirow{2}{*}{$\begin{array}{l}\text { Father's occupational } \\
\text { status }\end{array}$} & Employed & $13(46.4 \%)$ & $15(53.6 \%)$ & \multirow{2}{*}{$\begin{array}{l}\text { Fisher exact } \\
\text { test }\end{array}$} & \multirow[t]{2}{*}{0.61} \\
\hline & Unemployed & $1(25.0 \%)$ & $3(75.0 \%)$ & & \\
\hline \multirow{2}{*}{$\begin{array}{l}\text { The number of affected } \\
\text { siblings having PKU }\end{array}$} & 1 & $11(44.0 \%)$ & $14(56.0 \%)$ & \multirow{2}{*}{$\begin{array}{l}\text { Fisher exact } \\
\text { test }\end{array}$} & \multirow[t]{2}{*}{1} \\
\hline & 2 & $3(42.9 \%)$ & $4(57.1 \%)$ & & \\
\hline
\end{tabular}

Good metabolic control had no statistically significant relation with any of the social and demographic characteristics assessed in this study.

\section{4- Discussion}

According to the study performed by Hartnett et al. in 2013, there was not any statistically meaningful relation between patient age and blood phenylalanine level, which is similar to the result of our study (20). On the other hand, based on a study performed by Cotugno et al. in 2011 , patient age and the metabolic control of the disease are statistically related, and those over 10 years old have better metabolic control (21). As a rule, older patients are better oriented regarding the importance of appropriate diet and potential complications of poor metabolic control. In order to find the cause of lack of relation between age and metabolic control in our study, the history of national phenylketonuria screening program in Iran must be considered. The national phenylketonuria screening program in Iran has been started since 2012; and our study was performed in 2019. In our study, children who have been screened by the national phenylketonuria screening program were 8 years old or younger; and children older than 8 years old have not been screened. Delayed diagnosis of phenylketonuria in those over 8 years old is usually associated with negative effects on cognitive and intellectual abilities of these children, which could account for the lack of good metabolic control among older individuals.

In a study performed by Cotugno et al. in 2011 and Freehauf et al. in 2013, there was no statistically meaningful relation between gender and metabolic control of the disease, which is similar to the result of our study. On the other hand, MacDonald et al. have stated that gender and phenylalanine blood level are statistically related; their study was performed on a small sample size of patients aged between 6 to 17 years old. Although few studies with small sample size have reported a significant relation between gender and metabolic control of the disease, systematic review articles do not approve any relation between these two factors. Our results are similar to the results of the vast majority of reliable researches performed in this field.

In two studies performed by Reber et al. in 1987 and Fehrenbach et al. in 1989, there were no relation between parent`s marital status and metabolic control of patients; regarding marital status, the results of our study was the same $(24,25)$.

According to recent studies performed by MacDonald A et al. in 2008, Alaei M et al. in 2011, and Olsson et al. in 2007 there were no statistically significant relation between parents' educational status and the metabolic control of the disease $(18,26,27)$; these findings are similar to our study results.

In studies performed by Griffiths P et al. in 2000 and Alaei $\mathrm{M}$ et al. in 2011, family income and metabolic control of the disease were statistically related (18, 29). On the other hand, MacDonald, A et al. in 2008 reported no relation between family income and metabolic control of the disease, which was similar to the results of our study; the lack of relation between these two factors could be an indicator of improvement in health care system and better insurance coverage (26). 
Based on the results of our study, the metabolic control of patients living in Birjand, the capital of South Khorasan province, is the same as those living out of Birjand; the lack of difference between the two groups of patients could be due to expansion of healthcare centers across the province.

According to the study performed by Alaei M et al. in 2011 the metabolic control of the disease was negatively affected by the number of affected siblings having PKU; on the other hand, based on the results of our study these two factors are not statistically related (18). Having more than one affected child could be both a financial and psychiatric burden; but as mentioned above, improved healthcare system and insurances have probably reduced the effects of these factors.

\section{1- Limitations}

As the number of known cases in South Khorasan province is limited, small sample size could be one of the main limitations of our study.

We also believe that there could be other possible socioeconomic and psychiatric factors that might affect blood phenylalanine level in patients having phenylketonuria.

\section{5- Conclusion}

Demographic and social factors including age, gender, parentsmaritalstatus, parents occupational status, the distance between home and phenylketonuria clinic (living in Birjand city or living outside Birjand city), and the number of affected siblings having phenylketonuria were not statistically related to metabolic control of disease in patient having phenylketonuria is South Khorasan province.

\section{6- Declarations}

\section{1- Ethics approval and consent to participate}

This study has been performed in accordance with the Declaration of Helsinki. This study has been granted an exemption from requiring ethics approval by Biomedical Research Ethics Committee of Birjand University of Medical Sciences. Further information and documentation to support this could be available on request.

Parents or legal guardians' informed consent was obtained before participation in the study. The aim of the present study was also explained to the patients' parents or legal guardian. Participation in this study imposed no costs on patients.

\section{2- Consent for publication}

Consent for publication was also obtained from parents or legal guardians.

\section{3- Availability of data and material}

The datasets used and/or analyzed during the current study are available from the corresponding author on reasonable request.

\section{4- Competing interests}

The authors declare that they have no competing interests.

\section{5- Funding}

This study did not receive any funding or financial support.

\section{6- Authors contribution}

TC designed the study and supervised all steps of this study; she is also the chief manager of phenylketonuria clinic in South Khorasan Province. BB performed the data analysis and interpreted data. EA and SS gathered the data through personal interviews and assessing the documents. NH was responsible for literature review; she also played a role in designing the study, and wrote the manuscript. All authors read and approved the final manuscript.

\section{7- Acknowledgements}

Not applicable.

\section{References}


1. Scriver, C.R., The metabolic \& molecular bases of inherited disease. Vol. 4. 2001: New York; Montreal: McGraw-Hill.

2. Badiee, S., et al., Epidemiological and clinical study of phenylketonouria (PKU) disease in Khorasan Province; Northeast Iran. medical journal of mashhad university of medical sciences, 2014. 57(3): p. 571-578.

3. Senemar, S., et al., Epidemiological and clinical study of Phenylketonuria (PKU) disease in the National Screening Program of Neonates, Fars province, Southern Iran. Iranian Journal of Public Health, 2009: p. 58-64.

4. Ganji, F., et al., Assessing the Phenylketonuria Screening Program in Newborns, Iran 2015-2016. Acta Medica Iranica, 2018: p. 49-55.

5. Waisbren, S.E., et al., Phenylalanine blood levels and clinical outcomes in phenylketonuria: a systematic literature review and meta-analysis. Molecular genetics and metabolism, 2007. 92(1-2): p. 63-70.

6. Blau, N., Genetics of phenylketonuria: then and now. Human mutation, 2016. 37(6): p. 508-515.

7. Medford, E., D.J. Hare, and A. Wittkowski, Demographic and psychosocial influences on treatment adherence for children and adolescents with PKU: a systematic review, in JIMD Reports, Volume 39. 2017, Springer. p. 107-116.

8. MacDonald, A., et al., Retrospective, observational data collection of the treatment of phenylketonuria in the UK, and associated clinical and health outcomes. Current medical research and opinion, 2011. 27(6): p. 1211-1222.

9. Scriver, C.R., Hyperphenylalaninemia: phenylalanine hydroxylase deficiency. The metabolic \& molecular bases of inherited disease, 2002: p. 1667-1724.

10. Rocha, J.C. and M.J. Martins, Oxidative stress in phenylketonuria: future directions. Journal of inherited metabolic disease, 2012. 35(3): p. 381-398.

11. Koch, R., et al., Phenylketonuria in adulthood: a collaborative study. Journal of inherited metabolic disease, 2002. 25(5): p. 333-346.

12. Van Spronsen, F.J., Phenylketonuria: a 21 st century perspective. Nature Reviews Endocrinology, 2010. 6(9): p. 509-514.

13. Brumm, V., D. Bilder ,and S. Waisbren, Psychiatric symptoms and disorders in phenylketonuria. Molecular genetics and metabolism, $2010.99: \mathrm{p}$. S59-S63.

14. Vallian, S., E. Barahimi, and H. Moeini, Phenylketonuria in Iranian population: a study in institutions for mentally retarded in Isfahan. Mutation Research/Fundamental and Molecular Mechanisms of Mutagenesis, 2003. 526(1-2): p. 45-52.

15. Anjema, K., et al., PKU: high plasma phenylalanine concentrations are associated with increased prevalence of mood swings. Molecular genetics and metabolism, 2011. 104(3): p. 231-234.

16. Viau, K.S., et al., Correlation of age-specific phenylalanine levels with intellectual outcome in patients with phenylketonuria. 2011. 34(4): p. 963-971.

17. Habib, A., et al., Incidence of phenylketonuria in Southern Iran. Iranian Journal of Medical Sciences, 2010. 35(2): p. 137-139.

18. Alaei, M., et al., Family social status and dietary adherence of patients with phenylketonuria. 2011. 21(3): p. 379.

19. Mahmoudi-Gharaei, J., S. Mostafavi, and N. Alirezaei, Quality of life and the associated psychological factors in caregivers of children with PKU. Iranian journal of psychiatry, 2011. 6(2): p. 66.

20. Hartnett, C., et al., Long-term outcomes of blood phenylalanine concentrations in children with classical phenylketonuria. Molecular genetics and metabolism, 2013. 108(4): p. 255-258. 49

21. Cotugno, G., et al., Adherence to diet and quality of life in patients with phenylketonuria. Acta Paediatrica, 2011. 100(8): p. $1144-1149$.

22. Freehauf, C., et al., Impact of geographic access to care on compliance and metabolic control in phenylketonuria. Molecular genetics and metabolism, 2013. 108(1): p. 13-17.

23. MacDonald, A., et al., Retrospective, observational data collection of the treatment of phenylketonuria in the UK, and associated clinical and health outcomes. 2011. 27(6): p. 1211-1222.

24. Reber, M., A.E. Kazak, and P. Himmelberg, Phenylalanine control and family functioning in early-treated phenylketonuria. Journal of Developmental and Behavioral Pediatrics, 1987.

25. Fehrenbach, A.M. and L. Peterson, Parental problem-solving skills, stress, and dietary compliance in phenylketonuria. Journal of Consulting and Clinical Psychology, 1989. 57(2): p. 237.

26. MacDonald, A., et al., Does maternal knowledge and parent education affect blood phenylalanine control in phenylketonuria? Journal of human nutrition and dietetics, 2008. 21(4): p. 351-358.

27. Olsson, G.M., S.M. Montgomery, and J. Alm, Family conditions and dietary control in phenylketonuria. Journal of inherited metabolic disease, 2007. 30(5): p. 708.

28. Shulman, S., et al., Children with phenylketonuria: the interface of family and child functioning. Journal of developmental and behavioral pediatrics: JDBP, 1991. 12(5): p. 315-321.

29. Griffiths, $\mathrm{P}$,.et al., Wechsler subscale IQ and subtest profile in early treated phenylketonuria. Archives of Disease in Childhood, 2000. 82(3): p. 209-215.

\section{Figures}




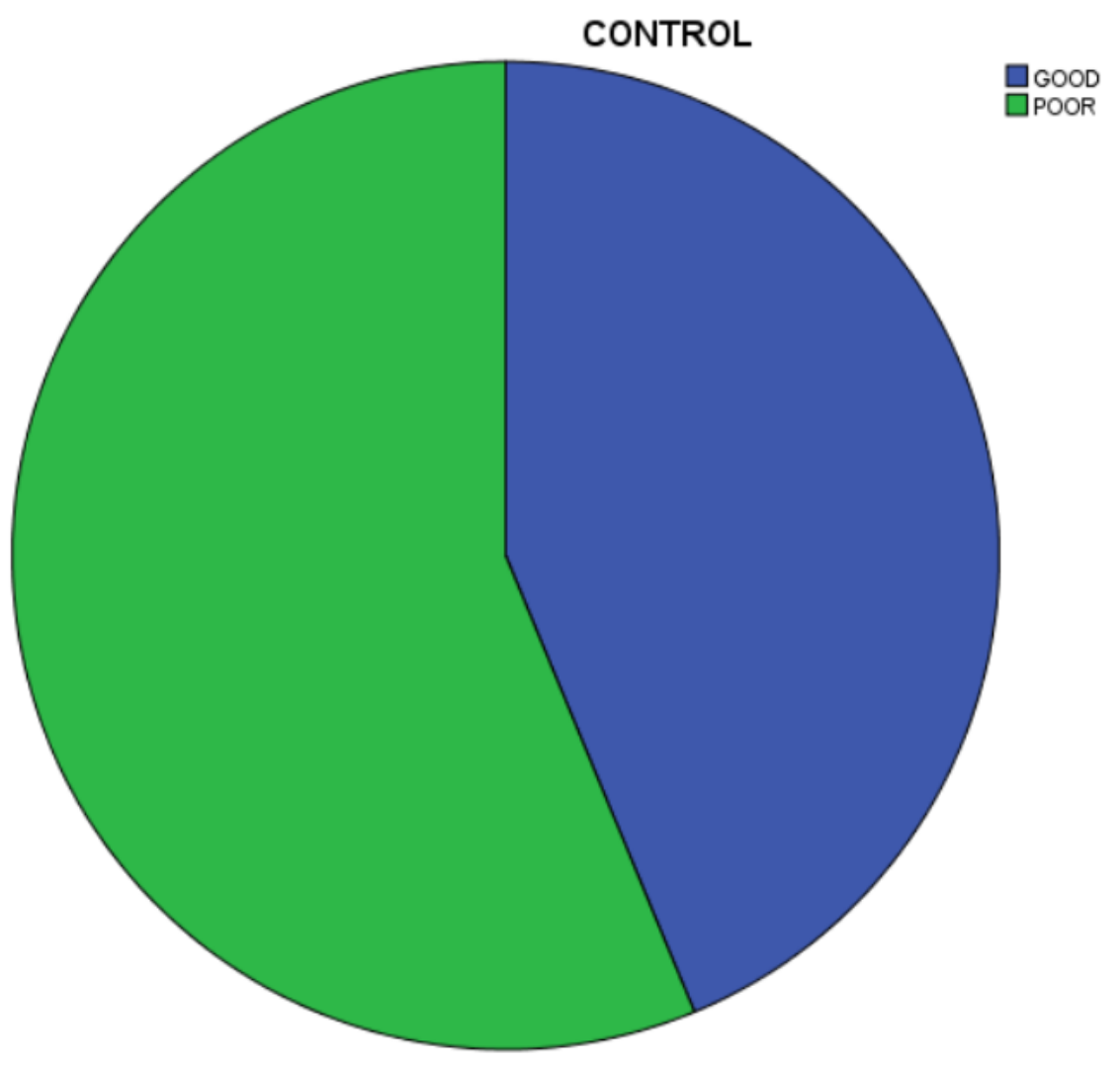

\section{Figure 1}

The metabolic control of 14 patients (43.3\%) was acceptable, and 18 patients (56.3\%) had poorly controlled blood phenylalanine levels. 